\title{
A bat on the brink? A range-wide survey of the Critically Endangered Livingstone's fruit bat Pteropus livingstonif-CORRIGENDUM
}

\author{
Bronten M. Daniel, Kathleen E. Green, Hugh Doulton \\ Daniel Mohamed Salim, Ishaka Said, Michael Hudson, Jeff S. Dawson \\ Richard P. Young and Amelaid Houmadi
}

DOI:10.1017/S0030605316000521. Published online by Cambridge University Press, 29 November 2016

In the above publication, Amelaid Houmadi, was omitted in error from the list of authors. This error has now been rectified in the original article. The updated Author contributions and Biographical sketches are below.

\section{Author contributions}

BD led the data collection, data analysis and drafting of the article. KG conducted data collection and analysis and made comments on the article. HD helped draft and edit the article. DS, AH and IS advised on survey design and collected field data. $\mathrm{MH}$ and JD supported data analysis and provided comments on the article. RY oversaw the design and delivery of the study and drafted and edited the article.

\section{Biographical sketches}

Bronwen Daniel and Kathleen Green were involved in a major terrestrial biodiversity assessment of the Comoros, including surveying Livingstone's fruit bat. Hugh Doulton is Technical Director of the Comorian NGO Dahari, for whom AmeLAid Houmadi, Ishaka SAID and Daniel Salim work as ecological technicians. They have worked together on ecological research in the Comoros for the past 8 years and are currently implementing a major Critical Ecosystem Partnership Fund programme to identify conservation priorities on Anjouan, as well as piloting a payment for ecosystem services approach to protecting key roost sites of Livingstone's fruit bat. Mike Hudson and JefF Dawson are conservation scientists. Richard Young was the lead scientist on the Comoros biodiversity assessment.

\section{Reference}

Daniel, B.M., Green, K.E., Doulton, H., Mohamed Salim, D., SAID, I., Hudson, M. et al. (2016) A bat on the brink? A rangewide survey of the Critically Endangered Livingstone's fruit bat Pteropus livingstonii. Oryx, https://doi.org/10.1017/ Soo30605316000521. 